\title{
Geometria do embasamento rochoso da BTS utilizando sísmica de alta resolução
}

Átila Saraiva Quintela Soares*(IGEO-UFBA) \& José Maria Landim Dominguez(IGEO-UFBA) \& Raissa Helena Simões Campos(IGEO-UFBA) \& Rafael Fonseca Ribeiro(IGEO-UFBA) \& Isaac de Oliveira Santos(IGEO-UFBA)

Copyright 2018, SBGf - Sociedade Brasileira de Geofísica Este texto foi preparado para a apresentação no VIII Simpósio Brasileiro de Geofísica, Salinópolis, 18 a 20 de setembro de 2018. Seu conteúdo foi revisado pelo Comitê Técnico do VIII SimBGf, mas não necessariamente representa a opinião da SBGf ou de seus associados. É proibida a reprodução total ou parcial deste material para propósitos comerciais sem prévia autorização da SBGf.

\section{Resumo}

During most of the last $500 \mathrm{kyr}$, the Todos os Santos bay (BTS) was exposed to sub-air conditions, and therefore to erosion. Only during brief intervals of time, the bay existed as such, as it currently does. The deposition of sediments occured only during these brief periods of inundation. Informations about the depth of the rocky substratum, and about the thickness of the acumulated sediment layer are very important to guide various engineering interventions, like dredging, ductwork, bridge construction, etc. With this in mind, this work is the result of a compilation of shallow high resolution seismic data, acquired during the last 12 years by the Coastal Studies Laboratory (Laboratório de Espaços Costeiros) - UFBA, and it had the objective of producing two maps; being one of the rocky basement topography, and the other of the thickness of the quaternary sediment layer, deposited above this paleo-topography.

\section{Introdução}

A baía de Todos os Santos (BTS) está implantada sobre rochas sedimentares cretácicas da Bacia do Recôncavo e teve sua origem e história evolutiva significativamente controlada pelas variações do nível do mar durante o Quaternário, causadas pelo avanço e recuo dos lençóis de gelo em altas latitudes. Neste período o nível do mar eustático experimentou oscilações da ordem de dezenas de metros em pouco milhares de anos (DOMINGUEZ; BITTENCOURT, 2009). Assim, por exemplo, a cerca de 20 ka (Último Máximo Glacial - UMG) o nível do mar encontrava-se 125 metros abaixo do nível atual e a BTS estava completamente exposta a condições subaéreas, bem como à erosão e incisão da rede de drenagem (DOMINGUEZ; BITTENCOURT, 2009).

Desde o UGM o nível do mar subiu cerca de $125 \mathrm{~m}$ até alcançar aproximadamente o nível atual por volta de 7-8 ka, tendo início a sedimentação Holocênica, que começou a soterrar o paleo-relevo gerado durante a exposição sub-aérea (DOMINGUEZ; BITTENCOURT, 2009).

O objetivo deste trabalho foi o de reconstruir o paleorelevo da BTS, quando a mesma esteve completamente exposta a condições sub-aéreas, assim como obter uma estimativa do volume de sedimentos acumulados sobre este paleo-relevo desde a última inundação pelo mar. Para tal, foram utilizados registros sísmicos de alta resolução adquiridos nos últimos 10 anos para confecção de mapas de espessura de sedimento e profundidade do embasamento rochoso. Trabalhos anteriormente realizados produziram mapas com estas informações apenas para trechos localizados da BTS (e.g. Campos (s.d.) e Valle (s.d.))

Os mapas produzidos e aqui apresentados servirão de apoio para a localização de possíveis jazidas de areia para uso na engenharia civil; principalmente na recuperação de praias, no planejamento e elaboração de projetos de dragagem, implantação de dutos, portos, pontes etc, além de usos acadêmicos como a investigação detalhada da origem e evolução da BTS.

\section{Metodologia}

Foram utilizados cerca de $814 \mathrm{~km}$ de linhas sísmicas de alta resolução sendo 568 adquiridas utilizando uma fonte CHIRP (frequência 2-19 Hz), e 246 com fonte Boomer (frequência 0,7-2 Hz). A disposição espacial está na figura 1.

Estes perfis foram interpretados utilizando os princípios da sismo-estratigrafia de modo a identificar o topo do embasamento rochoso, constituído pelas rochas sedimentares da bacia do Recôncavo e o fundo marinho. A diferença entre estas duas superfícies fornece o valor da espessura de sedimentos quaternários acumulados. A marcação destas duas superfícies foi feita utilizando os aplicativos SonarWiz $® e$ Meridata MDPS ${ }^{\circledR}$. (OBS: coloque o simbolo de marca registrada em superescrito ao lado dos nomes dos dois aplicativos).

Os dados obtidos foram utilizados para a confecção dos mapas da topografia do embasamento rochoso (paleobatimetria) e de espessura de sedimentos (isópacas). Para que a interpolação dos valores destes dois parâmetros, para regiões entre as linhas sísmicas, utilizouse o algoritmo de krigagem, implementado no aplicativo Surfer $10 \AA$. O valor " 0 " foi aplicado para a profundidade do embasamento rochoso ao longo da linha de costa no entorno da baia, bem como no entorno de suas ilhas e lajes rochosas, comuns na região norte da BTS. As maIhas de pontos obtidas foram filtradas utilizando-se um filtro gaussiano, aplicando-se 10 iterações, de modo a evitar a produção de artefatos devido a variação na densidade espacial dos dados, os quais estão concentrados ao longo das linhas sísmicas.

As malhas de pontos filtradas foram importadas para o aplicativo QGIS de Sistema de Informação Geográfica (SIG) para interpretação, aplicação de efeitos de sombre- 


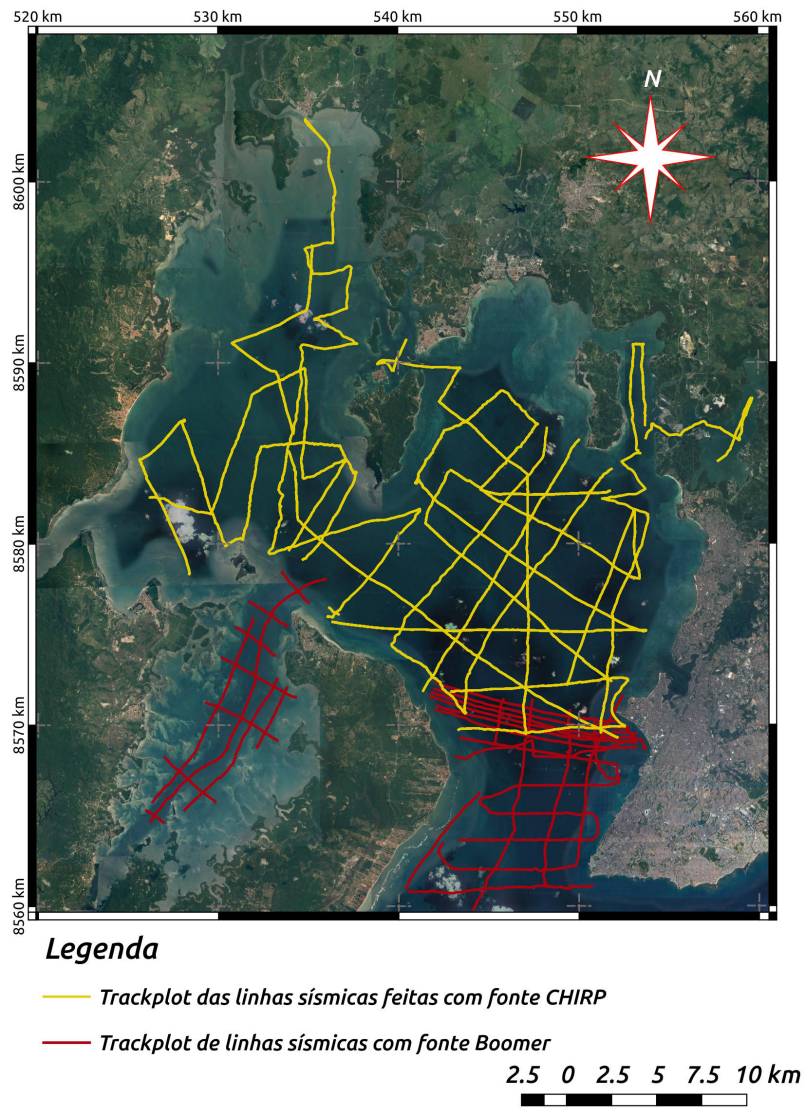

Figura 1: Plot dos pontos interpolados das linhas sísmicas, e qual foi a fonte sísmica utilizada na sua respectiva aquisição. Pontos roxos indicam dados adquiridos com Boomer e os vermelhos adquiridos com CHIRP. Mapa de fundo disponibilizado por Bing Aerial

amento e produção dos mapas finais.

\section{Resultados e Discussão}

Os resultados obtidos estão apresentados nas figuras 2 e 4 .

O mapa do relevo do topo do embasamento rochoso, mostra que as regiões mais rebaixadas deste paleorelevo coincidem com os dois atuais canais principais da BTS, os canais de Salvador e Itaparica. Outras regiões topograficamente rebaixadas estão presentes na porção NE da BTS, e uma feição em canal orientada WE entre a foz do Paraguaçu e a extremidade sul da ilha do Frade. Estas regiões coincidem nos dias atuais com as áreas mais profundas da BTS. Isto mostra que a morfologia da BTS não foi significativamente alterada pela inundação do nível do mar em comparação com aquele existente quando a baia estava exposta sub-aereamente.

Sobre o mapa da figura 2 plotamos o que poderia ter sido a paleo-drenagem existente na BTS na época de sua completa exposição sub-aérea. As maiores espessuras de sedimentos acumulados coincidem aproximadamente com os eixos desta paleo-drenagem, à exceção do trecho do canal de Salvador próximo à entrada da BTS. Além disso, calculou-se que um volume de cerca de $6,97 \mathrm{~km} 3$ de sedimentos encontra-se armazenado na BTS.

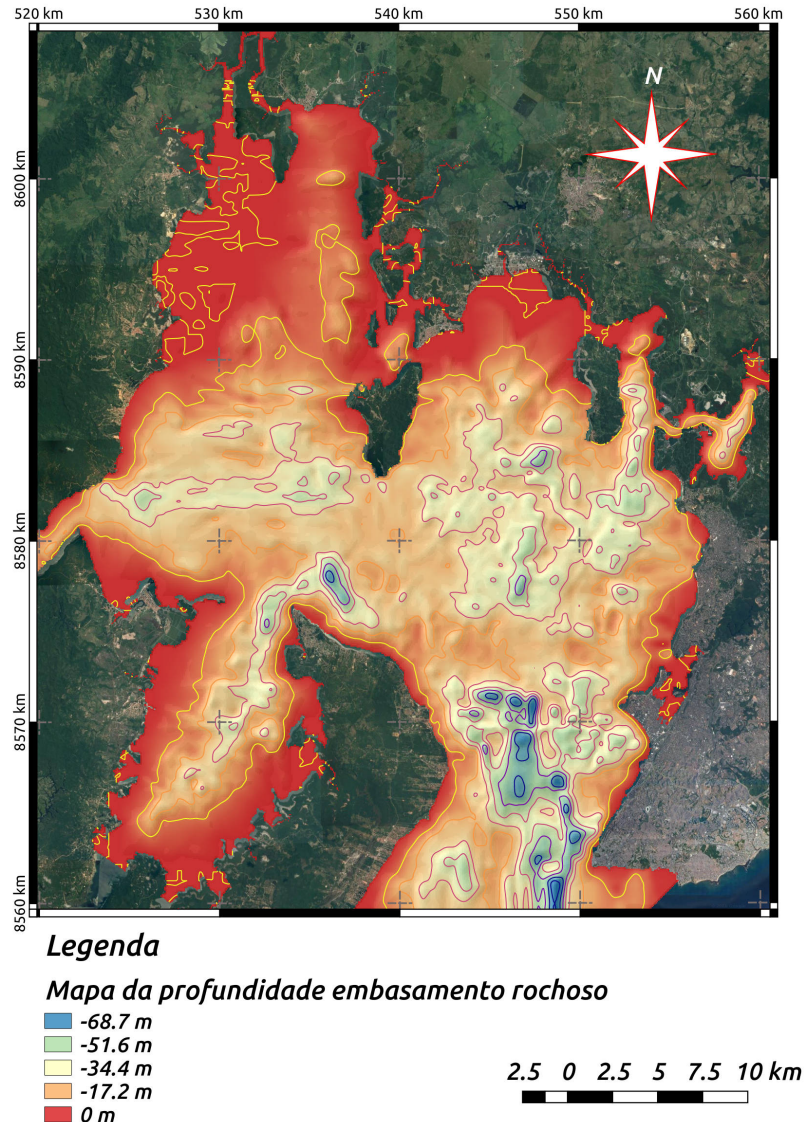

Figura 2: Mapa da profundidade do embasamento rochoso. Quanto mais escuro, tendendo para o azul, mais profundo, como na legenda.

\section{Conclusões}

Este trabalho resultou na elaboração de um mapa do paleo-relevo do embasamento rochoso esculpido principalmente por processos de erosão sub-aérea, que predominaram na região nos últimos $500 \mathrm{ka}$. Este paleo-relevo foi inundado durante a subida do nível do mar desde o Último Máximo Glacial resultando na BTS como conhecemos hoje. De todo modo, a batimetria atual da BTS não difere significativamente do paleo-relevo do topo do embasamento rochoso, indicando que um volume reduzido de sedimentos se acumulou. De fato, o volume total de sedimentos acumulados da ordem de $7 \mathrm{~km} 3$ representa apenas $39,18 \%$ do volume original de espaço de acomodação disponível. A principal causa para esta acumulação limitada de sedimentos é a ausência de uma rede de drenagem expressiva desaguando na baía.

\section{Agradecimentos}

Este trabalho foi realizado no âmbito do do inctAmbTropic - Instituto Nacional de Ciência e Tecnologia em Ambientes Marinhos Tropicais, CNPq/FAPESB Processos: $565054 / 2010-4$, 8936/2011 e 465634/2014-1. ASQ Soares é bolsista do PIBIC. 


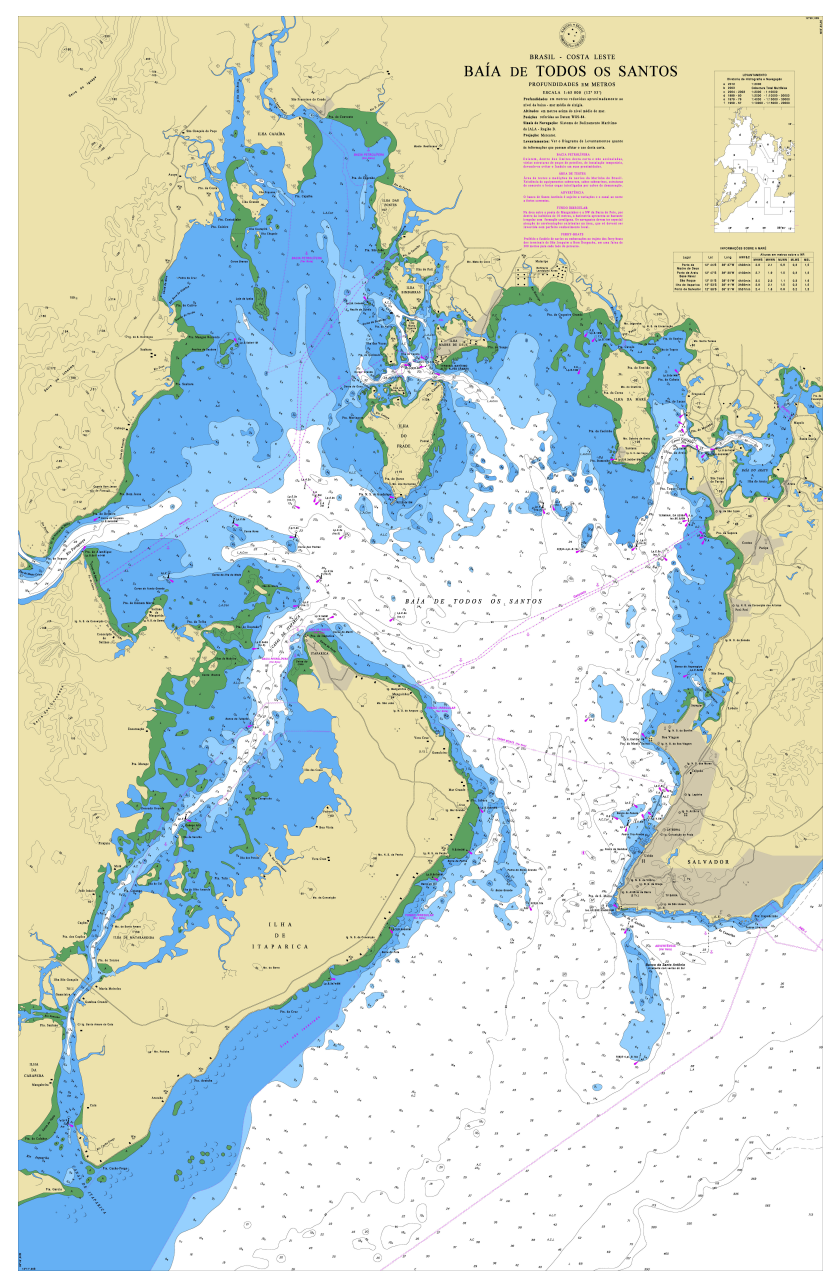

Figura 3: Carta náutico da Diretoria de Hidrologia e Navegação (DHN)

\section{Referências}

CAMPOS, Raissa Helena Simões. Ocorrência de gás nos sedimentos holocênicos da Baía de Todos os Santos: Origem e Distribuição. Monografia Universidade Federal da Bahia, Salvador, 2010.

DOMINGUEZ, José M. L.;

BITTENCOURT, Abílio C. S. P. Geologia. In: HATJE, Vanessa; ANDRADE, Jailson B de. Baía de Todos os Santos: aspectos oceanográficos. Salvador: EDUFBA, 2009. p. 25-66.

VALLE, Marcio Martins. Hístória do preenchimento sedimentar da porção nordeste da Baía de Todos os Santos, Bahia, Brasil, e sua influência sobre a evolução dos hábitats bentônicos. Monografia Universidade Federal da Bahia, Salvador, 2013.

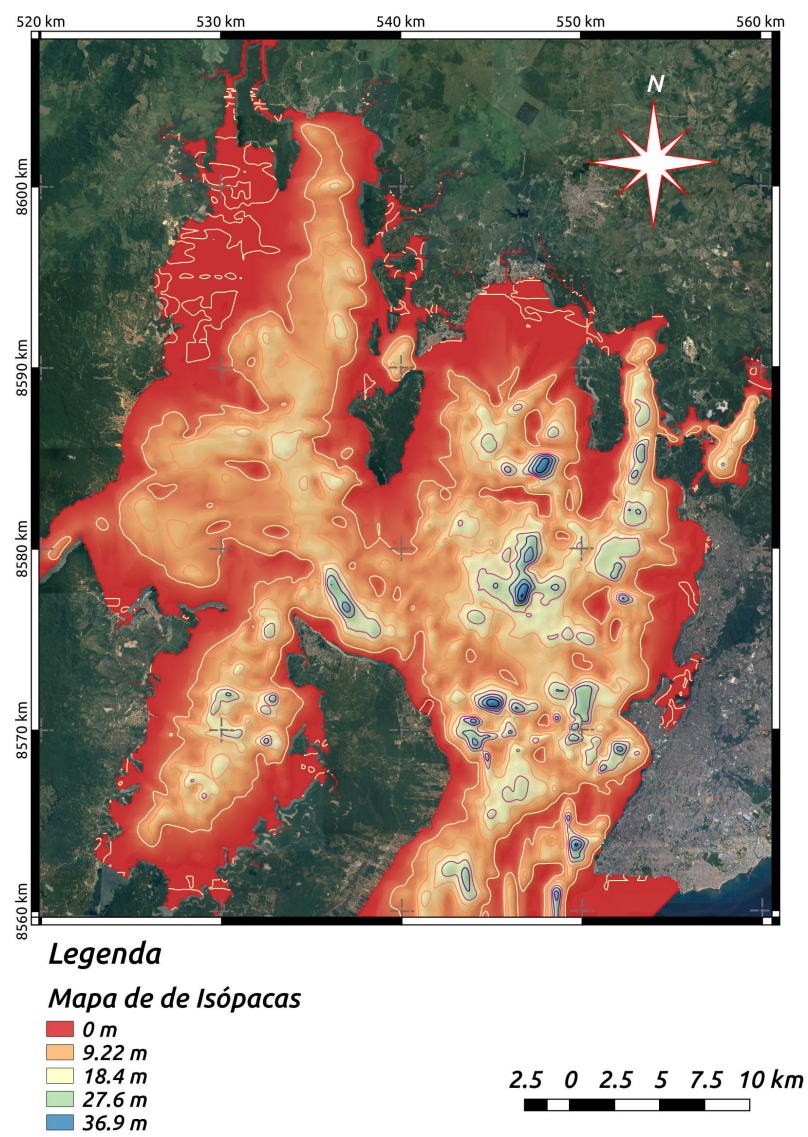

Figura 4: Mapa da espessura da distribuição espacial da espessura da cobertura sedimentar Quaternária. Quanto mais escuro, tendendo para o azul, mais espesso, como na legenda. 